\title{
Work-associated Arthritis Productivity Loss: Where Do We Stand in Its Measurement?
}

Bernardino Ramazzini, the father of occupational medicine, recognized the association of the health of workers and their on-the-job productivity in his book Diseases of Workers, published in $1713^{1}$. Productivity loss associated with workers is related to time off work, termed absenteeism, and decrements in on-the-job productivity, termed presenteeism ${ }^{2}$. The measurement of absenteeism, whether from a portion of a workday or a full workday, is conceptually understandable and potentially objective to measure ${ }^{3}$. There are a wide variety of reasons for absences from work related to medical conditions, ranging from incidental or scattered absences to extended disability leave. Although there is general agreement that medical conditions such as arthritis can affect on-the-job productivity, there is no general agreement on its measurement, translation, or monetization.

Publications on the association of medical conditions with objectively measured on-the-job productivity have been relatively few and limited to such studies as anemia in factory workers ${ }^{4}$, nutritional status in tea pickers ${ }^{5}$, nutritional status in road construction workers ${ }^{6}$, and medical conditions and health risk factors in telephone call center workers ${ }^{7}$.

The majority of the studies related to presenteeism rely on various established questionnaires. There have been a number of reviews of the instruments that measure self-reported productivity $\operatorname{loss}^{8,9,10,11,12}$. Attendees at OMERACT 9 (Outcome Measures in Rheumatology Clinical Trials) reviewed 21 measures of job-related productivity loss, ranging from single to multiple questions ${ }^{13}$. At least 11 of these instruments have been used in employees with arthritis. There was general agreement on the measurement and importance of absenteeism and the importance of presenteeism. However, there was no endorsement of any of the current questionnaires to measure presenteeism until further research was conducted. The attendees outlined guidelines for a continued research agenda.

In this issue of The Journal, the research by Zhang, et al will no doubt add to the controversy over the measurement and monetization of presenteeism ${ }^{14}$. In a well designed study of 250 workers with either rheumatoid arthritis or osteoarthritis, they administered 4 of the most common questionnaires used to measure presenteeism, including the Health and Labor Questionnaire (HLQ), the Work Limitations Questionnaire (WLQ), the World Health Organization's Health and Work Performance Questionnaire (HPQ), and the Work Productivity and Activity Impairment Questionnaire (WPAI). All participants were working for the 2 weeks prior to the administration of the questionnaires. Both the estimated number of hours of work-related productivity loss in the previous 2 weeks and the cost of presenteeism varied significantly depending on the instrument used in the study. The number of hours lost ranged from 1.6 hours for the HLQ and 4.0 for the WLQ to a high of 13.5 and 14.2 hours for the HPQ and WPAI, respectively. The economic value of this on-the-job productivity loss was estimated to be $\$ 30.03, \$ 83.05, \$ 284.07$ and $\$ 285.10$ for each instrument, respectively. Although a few other studies have compared the economic value of lost productivity estimated by various instruments, this is the first study that we are aware of that provides a head-to-head comparison of these 4 instruments. Clearly there was little agreement between these questionnaires in regard to estimating presenteeism and the cost of the associated productivity loss. Similarly, there were variations in the associations between lost productivity and functional disability, pain, and arthritis severity in this comparison of instruments.

Current and future therapies for rheumatologic conditions may be very costly to payers such as employers and governmental bodies. Lacaille pointed out the importance of evaluating these therapies for their impact on employment status and productivity ${ }^{15}$. We concur with this assessment. However, at this time, the understanding of presenteeism in different populations and job types and its translation to dollars, along with other productivity measures such as absenteeism, workers compensation, and shortand longterm disability leave, is immature. The cost effectiveness, and ultimately, the willingness of payers to cover the cost of pharmaceutical and other interventions will depend in part on a validated method of evaluating their influence on worker productivity.

See Productivity loss due to presenteeism among patients with arthritis, page 1805.

Personal non-commercial use only. The Journal of Rheumatology Copyright @ 2010 . All rights reserved. 
The health management field should seek to attain consensus on a "gold standard" of measuring lost on-the-job productivity as well as the ability to convert such losses to dollars. We are not alone in our concerns. Prasad, et al reported that there is "little guidance in terms of the best approaches for measuring...productivity"10, while Evans stated that "it is difficult to determine which questionnaire is superior" and that the interpretation of most presenteeism results is "thorny"11. Questions surrounding the monetization issue were summarized by Mattke, et al, who maintain there is a "lack of an established and validated method to derive monetary estimates of the cost of lost productivity" 8 . Johns also raised many of these same concerns ${ }^{16}$, while Nicholson, et al stated that "many employers are skeptical about presenteeism in general" 17 . Calculations of presenteeism costs "have thus far failed to be universally persuasive to top management", state Pauly, et al $^{18}$. The skepticism is supported by the results from a Dutch review by Bernaards and Hendriksen ${ }^{19}$ and the research by van den Heuvel, et $a l^{20}$. It is clear that these concerns are reflected in the corporate world, where skepticism about presenteeism remains at a high level. These concerns can only be overcome with solid science and agreed-upon methodology. Zhang, et al ${ }^{14}$ have provided interesting results for the discussion of how best to measure and interpret presenteeism.

WAYNE N. BURTON, MD,

Adjunct Professor of Environmental and

Occupational Health Services,

University of Illinois at Chicago,

Chicago, Illinois;

ALYSSA SCHULTZ, PhD;

CHEN YU CHIN, PhD;

DEE W. EDINGTON, PhD,

University of Michigan Health Management Research Center, Ann Arbor, Michigan, USA

Address correspondence to Dr. Burton

E-mail:wayneburtonmd@comcast.net

\section{REFERENCES}

1. Ramazzini B. Diseases of workers. Chicago: University of Chicago Press; 1940

2. Burton WN, Brandt-Rauf PW. Health and productivity: A review of the state-of-the-art and implications for occupational and environmental medicine. G Ital Med Lav Erg 2008;30 Suppl:15-29.
3. Burton W, Morrison A, Maclean R, Ruderman E. Systematic review of studies of productivity loss due to rheumatoid arthritis. Occup Med 2006;56:18-27.

4. Utoro J, Gross R, Schultink W, Sedioetama D. The association between BMI and haemoglobin and work productivity among Indonesian female factory workers. Eur J Clin Nutr 1998;52:131-5.

5. Severatma RR. De Silva LD, Pathmeswaran A, De Silva NR. Nutritional status and productivity in Sri Lankan tea pickers. Ceylon Med J 2004;102:102-3.

6. Wolgemuth JC, Latham MC, Hall A, Chesher A, Crompton DWT. Worker productivity and the nutritional status of Kenyan road construction laborers. Am J Clin Nutr 1982;36:68-78.

7. Burton WN, Conti DJ, Chen CY, Schultz AB, Edington DW. The role of health risk factors and disease on worker productivity. J Occup Environ Med 1999;41:863-77.

8. Mattke S, Balakrishnan A, Bergamo G, Newberry SJ. A review of methods to measure health-related productivity loss. Am J Manag Care 2007;13:211-7

9. Schultz AB, Chen CY, Edington DW. The cost and impact of health conditions on presenteeism to employers: A review of the literature. Pharmacoeconomics 2009;27:365-78.

10. Prasad M, Wahlqvist P, Shikiar R, Shih YT. A review of self-report instruments measuring health-related work productivity. Pharmacoeconomics 2004;22:225-44.

11. Evans CJ. Health and work productivity assessment: State of the art or state of flux? J Occup Environ Med 2004;46:S3-S11.

12. Lofland JH, Pizzi L, Frick KD. A review of health-related workplace productivity loss instruments. Pharmacoeconomics 2004;22:165-84

13. Beaton D, Bombardier C, Escorpizo R, Zhang W, Lacaille D, Boonen A, et al. Measuring worker productivity: Frameworks and measures. J Rheumatol 2009;36:2100-9.

14. Zhang W, Gignac MAM, Beaton D, Tang K, Anis AH. Productivity loss due to presenteeism among patients with arthritis: estimates from 4 instruments. J Rheumatol 2010;37:1805-14.

15. Lacaille D. Arthritis and employment research: Where are we? Where do we need to go? J Rheumatol 2005;32 Suppl 72:42-5

16. Johns G. Presenteeism in the workplace: a review and research agenda. J Organ Behav 2009;31:519-42.

17. Nicholson S, Pauly MV, Polsky D, Sharda C, Szrek H, Berger ML. Measuring the effects of work loss on productivity with team production. Health Econ 2006;15:111-23.

18. Pauly MV, Nicholson S, Polsky D, Berger ML, Sharda C. Valuing reductions in on-the-job illness: 'presenteeism' from managerial and economic perspectives. Health Econ 2008;17:469-85.

19. Bernaards C, Hendriksen I. Measuring productivity by questionnaire: State of affairs. Leiden: TNO; 2007.

20. van den Heuvel SG, Geuskens GA, Hooftman WE, Koppes LL, van den Bossche SN. Productivity loss at work; health-related and work-related factors. J Occup Rehabil 2009. Epub ahead of print.

J Rheumatol 2010;37:1792-3; doi:10.3899/jrheum.100503 